\title{
Yurt Dışında Yaşayan İki Dilli Türk Çocukları İçin Yazlan Türkçe Öğretim Kitaplarındaki Atasözü ve Deyimlerin Değerler Eğitimi Açısından İncelenmesi*
}

\author{
The Investigation of Properties and Experiences in Turkish Teaching Books Written for Bilingual \\ Turkish Children Living Abroad
}

\author{
Erhan Yeşilyurt** - Hilal Keskin ${ }^{* * *}$
}

\begin{abstract}
Türkçe ve Türk Kültürü Ders Öğretim Materyalleri” were prepared under the coordination of the Board of Education and Discipline for Turkish children living abroad to learn and protect their culture and to use Turkish correctly and effectively. It is more difficult for children who live abroad to protect their culture and learn their national values than Turks living in Turkey. Therefore, special attention should be paid to the education of values given to Turkish children living abroad. The language of the society is also affected by every event of the society experiences. Thus, the values obtained as a result of the lives of societies reach the era lived through owing to the language formed as a result of the experiences. The research is important as a guide to giving more importance to values education in new materials to be prepared for bilingual Turkish children living abroad. In this study, it is aimed to examine proverbs and idioms in Turkish teaching books written for bilingual Turkish children living abroad in terms of values education. To achieve this goal, "Türkçe ve Türk Kültürü Ders Öğretim Materyali (1-3, 4-5, 6-7, 8-10. Sınıflar), Türkçe ve Türk Kültürü Çalışma Kitabı (1-3, 4-5, 6-7, 8-10. Sinıflar)", "Türkçe ve Türk Kültürü Öğretmen Kılavuz Kitabı (1-10. Sınıflar)” were selected as samples. In the analysis of the idioms and proverbs in the Turkish and Turkish Culture Turkish teaching set, the value and the context in the proverbs and their context in the text were used. In the research, it is concluded that the most solidarity value is tried to be gained with proverbs and idioms in the teaching materials.
\end{abstract}

Structured Abstract: With the development of technology, some national and moral values have disappeared. Excessive and exaggerated use of technology causes the new generation to be deprived of many national and moral values. For this reason, it is very important to teach the basic building blocks of the societies and the values that have the ability to unite the individuals in the society in order to ensure the continuity of the

\footnotetext{
* Bu makale 3. Uluslararası Değerler Eğitimi Kongresi (05-06.04.2018)'nde sunulan sözlü bildirinin makale formatında hazırlanmış halidir.

** Dr. Öğr. Üyesi, Zonguldak Bülent Ecevit Üniversitesi, Eğitim Fakültesi, Türkçe ve Sosyal Bilimler Eğitimi Bölümü Asst. Prof. Dr. Zonguldak Bulent Ecevit University/Faculty Of Educatıon, Department of Social Sciences and Turkish Language Education

Received/Geliș: 16 June/Haziran 2020

Accepted/Kabul: 20 August/Ağustos 2020

Copyright $(\mathrm{C}$ INTAC LTD, Turkey
} 
societies. The concept of value is the social elements accepted and agreed upon by the society. For this reason, they are indispensable elements in ensuring social order. Values are unwritten social rules. Owing to the values, the desired and unwanted behavior patterns in the society are determined and the order of the society is provided. In order for societies to progress in this way, individuals should be informed about values education. Individuals first start to learn about values through their family. It is the first step of value teaching to bring the right and wrong behaviors to the individual by the family. The language of the society is also affected by every event of the society experiences. Thus, the values obtained as a result of the lives of societies reach the era lived through owing to the language formed as a result of the experiences. The most beautiful language examples of this situation are proverbs and idioms. According to the definition of TDK (2018), the proverb is "A word that is said and based on long trials and observations and is a public, admonition." Proverbs are formed as a result of the lives of societies, they are costly to society, they are short and concise words. Teaching of proverbs and idioms, which are seen as important resources for values education, is mostly done in Turkish lessons. The teaching of proverbs and idioms is extremely important in Turkish lessons, which are usually conducted as a native language in Turkey. However, there is an area where teaching proverbs and idioms is more important in terms of values education, which is teaching Turkish as a mother tongue abroad. Turkish children, who have to go abroad at a young age for various reasons, learn the language of the countries they visit as their mother tongue. Turkish children who have to learn both Turkish and the language of their country as their mother tongue at the same time experience a language learning complex. In terms of mother tongue learning, the concepts of "bilingualism" are used for Turkish children who are caught between this dilemma and "bilingualism" is used. The aim of the study is to examine the Turkish Language and Turkish Culture (Grades 1-10) Course Teaching Material, Workbook and Teacher Manual prepared by the Ministry of National Education with the decision of the Board of Education, dated 16.11.2009 and number 201 in terms of values education. The problem of the research is "What is the situation of proverbs and idioms in Turkish and Turkish Culture Books written for bilingual Turkish children living abroad?" Any studies have been conducted on Turkish and Turkish Culture (Grades 1-10) Course Instruction Material, Workbook and Teacher Guide books prepared by the Ministry of National Education in terms of values education. For this reason, it is important to examine the textbooks prepared within the framework of the implementation of the Turkish and Turkish Culture Curriculum in terms of values education, in order to reveal how the value transfer is. Document analysis method, one of the qualitative research methods, was used in the research. The study group of the research consists of Turkish and Turkish Culture (Grades 1-10) Course Instruction Material, Workbook and Teacher Guide books prepared by the Ministry of National Education. The materials were subjected to content analysis. In the content analysis, it is aimed to reach the concepts and relationships that can explain the collected data. In the analysis of proverbs and idioms in the "Turkish and Turkish Culture" books prepared for bilingual Turkish children in the teaching of value teaching, the Turkish and Turkish Culture Course Program for Turkish Children Abroad prepared for bilingual Turkish children (Grades 1-10) field core values are used. The values that are desired to be gained to the students are as follows (MEB, 2009: 3): Patriotism, tolerance, respect for differences, peace, sensitivity to maintaining cultural heritage, hospitality, solidarity, responsibility, sharing, honesty, helpfulness, aesthetic sensitivity. In the analysis of the idioms and proverbs in the Turkish and Turkish Culture Turkish teaching set, the value and the context in the proverbs and their context in the text were used. In the research, it is concluded that the most solidarity value is tried to be gained with proverbs and idioms in the teaching materials. In the new materials to be prepared to teach Turkish to bilingual Turkish children, all the values that should be gained should be included. The values that should be gained in new materials to be prepared to teach Turkish to bilingual Turkish children should be distributed equally to the materials. Proverbs and idioms should be used while adding value to students.

Keywords: Turkish Education, Idioms, Proverbs, Values education, Teaching Turkish to bilingual Turkish children.

Öz: Yurt dışında yaşayan Türk çocuklarının hem kültürlerini öğrenmeleri ve korumaları hem de Türkçeyi doğru ve etkili kullanmaları amacıyla Talim ve Terbiye Kurulu Başkanlığının koordinesinde Türkçe ve Türk Kültürü Ders Öğretim Materyalleri hazırlanmıştır. Yurt dışında yaşamını sürdüren çocukların kültürlerini korumaları ve milli değerlerini öğrenmeleri yurt içinde yaşayan Türklere göre daha zor olmaktadır. Bu nedenle yurt dışında yaşayan Türk çocuklarına verilen değerler eğitimine ayrıca özen gösterilmelidir. Bir toplumun yaşadığı her olaydan o toplumun dili de etkilenmektedir. Böylece toplumların yaşantıları sonucu elde edilen değerler, yine yaşantılar sonucunda şekillenen dil sayesinde içinde yaşanılan çağa kadar ulaşır. Araştırma yurt

Turkish Studies - Education, 15(4) 
dışında yaşayan iki dilli Türk çocuklarına yönelik hazırlanacak yeni materyallerde değerler eğitimine daha fazla önem verilmesine kılavuz olması açısından önemlidir. Bu araştırmada yurt dışında yaşayan iki dilli Türk çocukları için yazılan Türkçe öğretim kitaplarında yer alan atasözü ve deyimlerin değerler eğitimi açısından incelenmesi amaçlanmaktadır. Bu amaca ulaşmak için Türkçe ve Türk Kültürü Ders Öğretim Materyali (1-3, 4-5, 6-7, 8-10. Sınıflar), Türkçe ve Türk Kültürü Çalışma Kitabı (1-3, 4-5, 6-7, 8-10. Sınıflar), Türkçe ve Türk Kültürü Öğretmen Kılavuz Kitabı (1-10. Sınıflar) örneklem olarak seçilmiştir. Türkçe ve Türk Kültürü Türkçe öğretim setinde yer alan deyim ve atasözlerin içerdiği değerlerin analizinde değer ve atasözlerin içerdiği anlam ve metin içerisindeki bağlamından yararlanılmıştır. Araştırmada, ders öğretim materyallerinde atasözü ve deyimler ile en fazla dayanışma değerinin kazandırılmaya çalışıldığı sonucuna ulaşılmıştır.

Anahtar Kelimeler: Türkçe Eğitimi, Deyimler, Atasözleri, Değerler eğitimi, İki dilli Türk çocuklarına Türkçe öğretimi.

\section{Giriş}

Teknolojinin gelişmesiyle birlikte bazı milli ve manevi değerler yok olmaya yüz tutmuştur. Aşırı ve abartılı teknoloji kullanımı yetişmekte olan yeni neslin birçok milli ve manevi değerden mahrum kalmasına neden olmaktadır. Bu nedenle gelecek nesilleri yetiştirirken, toplumların temel yapı taşları ve toplumdaki bireyleri birleştirme özelliğine sahip olan değerleri öğretmek toplumların devamlılığını sağlamak adına son derece önemlidir.

Halstead ve Taylor (2000: 169) değeri, genel olarak davranışlara rehberlik eden ilkeler ve temel inançlar, eylemlerin iyi ya da istenilen olarak yargılandığı standartlar şeklinde ifade etmişlerdir. Değer ile ilgili tanımlara bakıldığında değer; toplum tarafından benimsenen, birleştirici ve bütünleştirici özellikler taşıyan, doğru ve gerekli olduğu düşünülen, ahlak ilkelerine uygun davranışlar olarak yorumlanmaktadır.

Değer kavramı, toplumun kabul ettiği, üstünde uzlaşmaya vardığı sosyal unsurlardır. Ayrıca değerler, varlığı nizam sağlayan, ancak yokluğu sebebiyle herhangi bir resmî cezai yaptırımı olmayan sosyal kabullerdir (Bulut, 2011). Bu sebeple toplumsal düzeni sağlamada vazgeçilmez unsurlardır. Bir başka ifadeyle değerler yazılı olmayan toplumsal kurallardır. Değerler sayesinde toplumdaki istendik ve istenmedik davranış modelleri belirlenerek toplumun düzeni sağlanır. Toplumların bu şekilde düzen içerisinde ilerleyebilmesi için bireylerin değerler eğitimi konusunda bilgilendirilmesi gerekmektedir. Bu nedenle toplumun değer yargılarının sistemli bir şekilde yeni nesillere aktarılmasında eğitimin rolü büyüktür. Eğitim değerlerden arınık değildir. Aksine değerler, eğitim sisteminde yol gösterici faktörlerdir (Kaymakcan ve Meydan, 2011: 30).

Bir toplumun kendine ait değerleri, o toplumun geçişte yaşadıkları olaylar sonucunda şekillenmektedir. Bunun sonucunda birey, geçmişini bilen ve aynı zamanda çağdaş bir bireyin sahip olması gereken bilgi, beceriler ile donanıp geleceğe yönelerek kendisinin farkında olmalıdır (Susar Kırmızı, 2014:219). Bireylerin bugün benimsedikleri milli, manevi ve kültürel değerlerin temelleri çok eski yıllara dayanmaktadır. Bu durumda, Geçmişteki değerlerin hala günümüzde benimseniyor olmasının sebebi nedir?" diye düşünüldüğünde bu sorunun cevabını şu şekilde vermek doğru olacaktır: Dil, milletlerle birlikte yaşadığ için onların etkilendiği her şeyden etkilenecektir; bu durum da kullanılan kelimelere yansıyacaktır (Bulut, 2011: 65). Kısacası bir toplumun yaşadığı her olaydan o toplumun dili de etkilenmektedir. Böylece toplumların yaşantıları sonucu elde edilen değerler, yine yaşantılar sonucunda şekillenen dil sayesinde içinde yaşanılan çağa kadar ulaşmıştır. Bu durumun en güzel dil örnekleri atasözleri ve deyimlerdir. TDK (2018)'nın tanımına göre atasözü, "Uzun deneme ve gözlemlere dayanılarak söylenmiş ve halka mal olmuş, ögüt verici nitelikte söz" dür. Yani atasözleri toplumların yaşantıları sonucunda oluşmuş, o topluma mal olmuş, öğüt verici, kısa ve özlü sözlerdir. Bu yönleriyle atasözleri toplumların yaşayışı hakkında içerisinde ipuçları barındıran en değerli hazinelerdir. Bir toplum, hangi değerleri benimsemişse dillerinde o değerlerle ilgili atasözlerine sıkça rastlanır (Bulut, 2011: 65). Deyim ise bir dili konuşan toplumun dünya görüşünü, 
yaşam biçimini, gelenek, görenek ve inançlarını, kısaca maddi ve manevi kültürünü yansıtan, o toplumun düşünce biçimini, hatta nükte ve buluşlarını ortaya koyan sözlerdir (Ertuğrul, 2005: 54). Atasözleri ve deyimler sayesinde milli, manevi ve kültürel değerler yeni nesillere aktarılarak toplumun fertleri arasında birlik ve beraberlik sağlanır. Söz konusu değerlerin yeni nesillere aktarılmaması sonucunda birbirini anlamayan, kültürel bakımdan kopuk, farklı değerleri benimseyen nesiller ortaya çıkar (Bulut, 2011: 63). Böyle bir duruma zemin hazırlamamak için atasözü ve deyimlerin yeni nesillere öğretilmesi gerekmektedir.

Değerler eğitimi için önemli kaynaklar olarak görülen atasözü ve deyimlerin öğretimi en çok Türkçe derslerinde yapılmaktadır. Yurt içinde genellikle ana dili olarak yapılan Türkçe derslerinde atasözü ve deyimlerin öğretimi son derece önemlidir. Fakat atasözü ve deyimlerin öğretiminin değerler eğitimi açısından çok daha önemli olduğu bir alan vardır ki o da yurt dışında ana dili olarak Türkçe öğretimidir. Çeşitli sebeplerle küçük yaşlarda yurt dışına gitmek durumunda kalan Türk çocukları gittikleri ülkelerin dilini ana dilleriymiş gibi öğrenmektedirler. Aynı anda hem Türkçeyi hem de yaşadıkları ülkenin dilini ana dili gibi öğrenmek durumunda kalan Türk çocukları bir dil öğrenim karmaşası yaşamaktadırlar. Ana dili öğrenimi açısından bu ikilem arasında kalan Türk çocukları için "iki dilli" söz konusu durum için ise "iki dillilik" kavramları kullanılmaktadır. Aksan (1998: 26) iki dilliliği, insanın çeşitli sebeplerle ve değişik şartlar altında birden fazla dili edinmesi, kullanması veya ikinci bir dili ana diline yakın düzeyde öğrenmesi olarak tanımlamaktadır. İki dillilik çok farklı durumlarda gerçekleşebilmektedir. Yurt dışında olduğu gibi yurt içinde de iki dilliliğin yaşandığı durumlar vardır. Ancak yurt dışındaki Türk çocuklarının içerisinde bulundukları iki dillilik durumu değerler eğitimi açısından daha zor bir süreci kapsamaktadır. Çünkü ülkesinden uzakta kalan bu çocukların milli, manevi ve kültürel değerlere uzaklığı da daha fazladır. Yaşadıkları ülkelerin değer yargılarını da öğrenen bu çocuklar Türkiye'ye döndüklerinde değer yargıları açısından ikilemde kalabilmektedirler. İki dilli diye tabir ettiğimiz bu çocuklar karşılaştıkları bir olay karşısında o olayın kendi değerleri açısından doğru mu yanlış mı olduğuna karar vermekte güçlük çekebilirler. Bunun sebebi karşılaştıkları olayın yaşadıkları ülkede doğru ama Türkiye'de ise yanlış bir davranış olarak değerlendirilmesidir. Bu durumun tam tersi şekilde değerlendirilmesi de yapılabilir. Bu nedenle yurt dışındaki Türk çocuklarının ana dili ve Türk kültürü öğretimleri üzerinde özenle durmak gerekmektedir.

Yurt dışındaki Türk çocuklarının kültürlerini korumaları ve milli değerlerini öğrenmelerinin en temel yolu iyi bir ana dili eğitimi almalarıdır. Bu bağlamda Türkçe ve Türk Kültürü Ders Öğretim Materyalleri hazırlanmıştır. Bu kitaplar sayesinde yurt dışındaki Türk çocuklarına ana dili olarak Türkçe ve Türk kültürü öğretimi yapılmaya başlanmıştır. Bu kitaplardaki metinler, atasözleri, deyimler vb. dil özellikleri sayesinde Türk kültürü ve değerleri yurt dışındaki Türk çocuklarına aktarılmaya çalışılmıştır.

Program çerçevesinde hazırlanan Türkçe ve Türk Kültürü Ders Öğretim Materyallerinin programın amacını ne derece gerçekleştirdiğine yönelik yapılan çalışmalar eksiktir. Bu açıdan araştırmanın amacı değerler eğitimi açısından Türkçe ve Türk Kültürü ders öğretim materyallerinin incelenmesidir.

Araştırmanın problemini "Yurt dışında yaşayan iki dilli Türk çocukları için yazılan Türkçe ve Türk Kültürü Kitaplarında yer alan atasözü ve deyimlerin değerler eğitimi açısından durumu nedir?" sorusu oluşturmaktadır. Probleme daha ayrıntılı cevap verebilmek için aşağıdaki alt problemlere ulaşılmıştır:

1. Türkçe ve Türk Kültürü 1-3. Sınıflar Ders Öğretim Materyalinde yer alan deyimler ve atasözlerinin değerler eğitimi açısından durumu nedir?

2. Türkçe ve Türk Kültürü 1-3. Sınıflar Çalışma Kitabında yer alan deyimler ve atasözlerinin değerler eğitimi açısından durumu nedir? 
3. Türkçe ve Türk Kültürü Öğretmen Kılavuz Kitab1 1-3. Sinıflar Dinleme Metinlerinde yer alan deyimler ve atasözlerinin değerler eğitimi açısından durumu nedir?

4. Türkçe ve Türk Kültürü 4-5. Sinıflar Ders Öğretim Materyalinde yer alan deyimler ve atasözlerinin değerler eğitimi açısından durumu nedir?

5. Türkçe ve Türk Kültürü 4-5. Sınıflar Çalışma Kitabında yer alan deyimler ve atasözlerinin değerler eğitimi açısından durumu nedir?

6. Türkçe ve Türk Kültürü Öğretmen Kılavuz Kitabı 4-5. Sınıflar Dinleme Metinlerinde yer alan deyimler ve atasözlerinin değerler eğitimi açısından durumu nedir?

7. Türkçe ve Türk Kültürü 6-7. Sinıflar Ders Öğretim Materyalinde yer alan deyimler ve atasözlerinin değerler eğitimi açısından durumu nedir?

8. Türkçe ve Türk Kültürü 6-7. Sınıflar Çalışma Kitabında yer alan deyimler ve atasözlerinin değerler eğitimi açısından durumu nedir?

9. Türkçe ve Türk Kültürü Öğretmen Kılavuz Kitab1 6-7. Sinıflar Dinleme Metinlerinde yer alan deyimler ve atasözlerinin değerler eğitimi açısından durumu nedir?

10. Türkçe ve Türk Kültürü 8-10. Sinıflar Ders Öğretim Materyalinde yer alan deyimler ve atasözlerinin değerler eğitimi açısından durumu nedir?

11. Türkçe ve Türk Kültürü 8-10. Sınıflar Çalışma Kitabında yer alan deyimler ve atasözlerinin değerler eğitimi açısından durumu nedir?

12. Türkçe ve Türk Kültürü Öğretmen Kılavuz Kitab1 8-10. Sınıflar Dinleme Metinlerinde yer alan deyimler ve atasözlerinin değerler eğitimi açısından durumu nedir?

Yapılan alan taramasında Türkçe ve Türk Kültürü kitaplarıyla ilgili çalışmalara bakıldığında hiçbirinin söz konusu kitapları değerler eğitimi açısından incelemediği görülmektedir. Bu çalışmanın amacı ise Türkçe ve Türk kültürü kitaplarındaki atasözü ve deyimleri değerler eğitimi açısından incelemektir. Araştırma yurt dışında yaşayan iki dilli Türk çocuklarına yönelik hazırlanacak yeni materyallerde değerler eğitimine daha fazla önem verilmesine kılavuz olması bakımından önemlidir.

Mete vd. (2018) makalelerinde Türkçe ve Türk Kültürü Dersi Öğretim Materyallerindeki atasözlerini belirleyerek kullanım sayısı ve sıklığını incelenmişlerdir. Sapsağlam (2016), Türkiye'de uygulanan okul öncesi eğitim programları $(1994,2002,2006$ ve 2013) hedef, amaç ve kazanımları referans değerler açısından incelenmiştir. Bulut (2013) makalesinde atasözleri ve deyimlerin rolleri ve Türkçe öğretimindeki işlevlerini incelemiştir. Deniz ve Uysal (2010) makalelerinde Yurt Dışındaki Türk Çocukları İçin Türkçe ve Türk Kültürü Öğretim Programını, Çerçeve Metin temelinde değerlendirmiş, Çerçeve ile Programın kesişen ve çelişen noktalarını belirlemişlerdir.

Milli Eğitim Bakanlığı tarafından iki dilli Türk çocukları için hazırlanan ders öğretim materyalleri üzerinde değerler eğitimi açısından herhangi bir çalışma yapılmamıştır. Bu nedenle materyallerin değer kazandırma açısından durumunun ortaya konması önemlidir.

\section{Yöntem}

\section{Araştırmanın modeli}

$\mathrm{Bu}$ araştırma nitel bir araştırmadır. Araştırmada doküman analizi kullanılmıştır. Doküman incelemesi, araştırılması hedeflenen olgu veya olgular hakkında bilgi içeren yazılı materyallerin analizini kapsar (Yıldırım ve Şimşek, 2005). 


\section{İnceleme Nesnesi}

Araştırmada çalışma grubu olarak Milli Eğitim Bakanlığı tarafından hazırlanan Türkçe ve Türk Kültürü (1-10. Sınıflar) Ders Öğretim Materyali, Çalışma Kitabı ve Öğretmen Kılavuz kitapları oluşturmaktadır.

\section{Verilerin toplanması}

Mili Eğitim Bakanlığı tarafından iki dilli Türk çocukları için hazırlanan Türkçe ve Türk Kültürü (1-10. Sınıflar) Ders Öğretim Materyali, Çalışma Kitabı ve Öğretmen Kılavuz kitapları incelenerek kitaplarda yer alan atasözü ve deyimlere ulaşılmıştır. Elde edilen veriler programda kazandırılmak istenen temel değerlere sahip olup olmaması açısından ayrıştırılmıştır.

\section{Verilerin analizi}

Mili Eğitim Bakanlığı tarafından iki dilli Türk çocukları için hazırlanan ders öğretim materyallerinin analizinde içerik analizi kullanılmıştır. $\mathrm{Bu}$ analizde, toplanan verileri açıklayabilecek kavramlara ve ilişkilere ulaşmak amaçlanmaktadır.

İki dilli Türk çocukları için hazırlanan "Türkçe Ve Türk Kültürü” kitaplarında yer alan atasözü ve deyimlerin değer öğretimine yönelik analizinde iki dilli Türk çocukları için hazırlanan Yurt Dışındaki Türk Çocukları İçin Türkçe ve Türk Kültürü Dersi Öğretim Programı (1-10. Sınıflar)'nda yer alan temel değerlerden yararlanılmıştır.

Programla öğrencilere kazandırılmak istenen değerler şunlardır (MEB, 2009: 3):

Vatanseverlik, hoşgörü, farklılıklara saygı duyma, barış, kültürel mirası yaşatmaya duyarlılık, misafirperverlik, dayanışma, sorumluluk, paylaşımcı olmak, dürüstlük, yardımseverlik, estetik duyarlilık.

Türkçe ve Türk Kültürü Türkçe öğretim setinde yer alan deyim ve atasözlerin içerdiği değerlerin analizinde deyim ve atasözlerin içerdiği anlam ve metin içerisindeki bağlamından yararlanılmıştır.

\section{Bulgular}

Türkçe ve Türk Kültürü 1-3. Sınıflar Ders Öğretim Materyalinde yer alan deyimler ve atasözlerinin değerler eğitimi açısından durumuna yönelik bulgular

Türkçe ve Türk Kültürü 1-3. Sınıflar Ders Öğretim Materyalinde sadece deyimlerin değer kazandırmada rolü bulunmaktadır. Türkçe ve Türk Kültürü 1-3. Sınıflar Ders Öğretim Materyalinde yer alan deyimlerin değerler eğitimi açısından durumu aşağıdaki tabloda yer almaktadır. 
Tablo 1: Türkçe ve Türk Kültürü 1-3. Sınıflar Ders Öğretim Materyalinde Yer Alan Deyimler Ve Atasözlerinin Değerler Eğitimi Açısından Durumu

\begin{tabular}{llll}
\hline Deyimler / Atasözleri & Türü & $\begin{array}{l}\text { Sayfa Numarası / } \\
\text { Kullanım Sılıı̆ı }\end{array}$ & Değerler \\
\hline Afiyet (afiyet şeker) olsun. & Deyim & 82 & Misafirperverlik \\
Davet etmek & Deyim & 86,173 & Misafirperverlik \\
El ele vermek & Deyim & 87,110 & Dayanışma \\
Elinden geleni yapmak & Deyim & 144 & Sorumluluk \\
Emanet bırakmak (etmek, vermek) & Deyim & 154 & Dayanı̧ma \\
Gönül açmak & Deyim & 51,78 & Yardımseverlik \\
Hoş geldiniz & Deyim & 81,84 & Misafirperverlik \\
Konuk etmek & Deyim & 142 & Misafirperverlik \\
Sözünde durmak & Deyim & 75 & Sorumluluk \\
Şehit düşmek (olmak) & Deyim & 163 & Vatanseverlik \\
Teselli etmek (vermek) & Deyim & 164 & Dayanış̧ma \\
Ziyaret etmek & Deyim & 89 & Dayanşma \\
\hline Toplam & & 16 adet & 5 değer \\
\hline
\end{tabular}

Türkçe ve Türk Kültürü 1-3. Sınıflar Ders Öğretim Materyalinde yer alan deyimler ve atasözleri değer kazandırma açısından incelendiğinde 12 adet deyimin 16 defa metinlerde kullanıldığı görülmektedir. Deyimler; misafirperverlik (f:6), dayanışma (f:5), sorumluluk (f:2), yardımseverlik (f:2) ve vatanseverlik (f:1) olmak üzere 5 farklı değerin kazandırılması açısından kullanılmıştır.

Türkçe ve Türk Kültürü 1-3. Sınıflar Çalışma Kitabında yer alan deyimler ve atasözlerinin değerler eğitimi açısından durumuna yönelik bulgular

Türkçe ve Türk Kültürü 1-3. Sınıflar Çalışma Kitabında sadece bir deyimin değer kazandırmada rolü bulunmaktadır. Türkçe ve Türk Kültürü 1-3. Sınıflar Çalışma Kitabında yer alan deyimin değerler eğitimi açısından durumu aşağıdaki tabloda yer almaktadır.

Tablo 2: Türkçe ve Türk Kültürü 1-3. Sınıflar Çalışma Kitabında yer alan deyimler ve atasözlerinin değerler eğitimi açısından durumu

\begin{tabular}{llll}
\hline Deyimler / Atasözleri & Türü & Sayfa Numarası / Kullanım Siklı̆̆ 1 & Değerler \\
\hline Yol göstermek & Deyim & 125 & Dayanışma \\
\hline Toplam & & 1 adet & 1 değer \\
\hline
\end{tabular}

Türkçe ve Türk Kültürü 1-3. Sınıflar Çalışma Kitabında yer alan deyimler ve atasözleri değer kazandırma açısından incelendiğinde 1 adet deyimin dayanışma değerinin kazandırılması açısından kullanıldığı görülmektedir.

Türkçe ve Türk Kültürü Öğretmen Kılavuz Kitabı 1-3. Sınıflar Dinleme Metinlerinde yer alan deyimler ve atasözlerinin değerler eğitimi açısından durumuna yönelik bulgular

Türkçe ve Türk Kültürü Öğretmen Kılavuz Kitabı 1-3. Sınıflar Dinleme Metinlerinde Türk Çocukları İçin Türkçe Ve Türk Kültürü Dersi Öğretim Programı (1-10. Sınıflar)'nda yer alan temel değerlere (MEB, 2009) yönelik bulgular yer almamaktadır.

Türkçe ve Türk Kültürü 4-5. Sınıflar Ders Öğretim Materyalinde yer alan deyimler ve atasözlerinin değerler eğitimi açısından durumuna yönelik bulgular

Türkçe ve Türk Kültürü 4-5. Sinıflar Ders Öğretim Materyalinde hem deyim hem atasözlerinin değer kazandırmada rolü bulunmaktadır. Türkçe ve Türk Kültürü 4-5. Sınıflar Ders Öğretim Materyalinde yer alan deyim ve atasözlerinin değerler eğitimi açısından durumu aşağıdaki tabloda yer almaktadır. 
Tablo 3: Türkçe ve Türk Kültürü 4-5. Sinıflar Ders Öğretim Materyalinde yer alan deyimler ve atasözlerinin değerler eğitimi açısından durumu

\begin{tabular}{llll}
\hline Atasözleri & Türü & $\begin{array}{l}\text { Sayfa Numarası/ } \\
\text { Kullanım Sıkığı }\end{array}$ & Değerler \\
\hline Bir elin nesi var, iki elin sesi var & Atasözü & 112 & Dayanışma \\
$\begin{array}{l}\text { Bir fincan kahvenin kırk yıl hatırı (hakkı) } \\
\text { var }\end{array}$ & Atasözü & 100 & Dayanısma \\
Afiyet (afiyet şeker) olsun & & & Misafirperverlik \\
Hoş geldiniz & Deyim & 102 & Misafirperverlik \\
Hâl hatır (hâlini hatırını) sormak & Deyim & 70 & Dayanışma \\
Kusura bakmamak (kalmamak) & Deyim & 159 & Hoşgörü \\
Şehit düşmek (olmak) & Deyim & 104 & Vatanseverlik \\
Ziyafet çekmek (vermek) & Deyim & 80,185 & Misafirperverlik \\
Ziyaret etmek & Deyim & $105(3)$ & Dayanışma \\
& Deyim & $9,16,20,22,67,87,94$ & \\
\hline Toplam & & $(2), 95,98,106(3), 159$, & \\
\hline
\end{tabular}

Türkçe ve Türk Kültürü 4-5. Sinıflar Ders Öğretim Materyalinde yer alan deyimler ve atasözleri değer kazandırma açısından incelendiğinde 2 adet atasözü ve 7 adet deyimin 29 defa metinlerde kullanıldığ 1 görülmektedir. Atasözleri ve deyimler; dayanışma (f:21), misafirperverlik (f:5), hoşgörü (f:1) ve vatanseverlik (f:2) olmak üzere 4 farklı değerin kazandırılması açısından kullanılmıştır.

Türkçe ve Türk Kültürü 4-5. Sınıflar Çalışma Kitabında yer alan deyimler ve atasözlerinin değerler eğitimi açısından durumuna yönelik bulgular

Türkçe ve Türk Kültürü 4-5. Sınıflar Çalışma Kitabında hem deyim hem atasözlerinin değer kazandırmada rolü bulunmaktadır. Türkçe ve Türk Kültürü 4-5. Sınıflar Çalışma Kitabında yer alan deyim ve atasözlerinin değerler eğitimi açısından durumu aşağıdaki tabloda yer almaktadır.

Tablo 4: Türkçe ve Türk Kültürü 4-5. Sınıflar Çalışma Kitabında yer alan deyimler ve atasözlerinin değerler eğitimi açısından durumu

\begin{tabular}{|c|c|c|c|}
\hline Atasözleri & Türü & $\begin{array}{l}\text { Sayfa Numarası / } \\
\text { Kullanım Siklığ } 1\end{array}$ & Değerler \\
\hline Birlikten kuvvet doğar & Atasözü & 100 & Dayanışma \\
\hline Komşu komşunun külüne muhtaçtır & Atasözü & 115 & Dayanışma \\
\hline $\begin{array}{l}\text { Misafir on kısmetle gelir, birini yer } \\
\text { dokuzunu bırakır }\end{array}$ & Atasözü & 91 & Misafirperverlik \\
\hline Sanat altın bilezik & Atasözü & 127,154 & $\begin{array}{l}\text { Estetik } \\
\text { duyarlılık }\end{array}$ \\
\hline Ziyaret etmek & Deyim & $28,66,114,144$ & Dayanışma \\
\hline Toplam & & 9 adet & 3 değer \\
\hline
\end{tabular}

Türkçe ve Türk Kültürü 4-5. Sınıflar Çalışma Kitabında yer alan deyimler ve atasözleri değer kazandırma açısından incelendiğinde 4 adet atasözü ve 1 adet deyimin 9 defa metinlerde kullanıldığ 1 görülmektedir. Atasözü ve deyimler; dayanışma (f:6), misafirperverlik (f:1) ve estetik (f:2) duyarlılık olmak üzere 3 farklı değerin kazandırılması açısından kullanılmıştır.

Türkçe ve Türk Kültürü Öğretmen Kılavuz Kitabı 4-5. Sınıflar Dinleme Metinlerinde yer alan deyimler ve atasözlerinin değerler eğitimi açısından durumuna yönelik bulgular

Türkçe ve Türk Kültürü Öğretmen Kılavuz Kitabı 4-5. Sınıflar Dinleme Metinlerinde sadece iki adet deyimin değer kazandırmada rolü bulunmaktadır. Türkçe ve Türk Kültürü Öğretmen Kılavuz 
Kitabı 4-5. Sınıflar Dinleme Metinlerinde yer alan deyimlerin değerler eğitimi açısından durumu aşağıdaki tabloda yer almaktadır.

Tablo 5: Türkçe ve Türk Kültürü 4-5. Sinıflar Dinleme Metinlerinde yer alan deyimler ve atasözlerinin değerler eğitimi açısından durumu

\begin{tabular}{llll}
\hline Atasözleri & Türü & $\begin{array}{l}\text { Sayfa Numarası / } \\
\text { Kullanım Sıklı̆̆ }\end{array}$ & Değerler \\
\hline Akıı danı̧̧mak & Deyim & 60 & Dayanışma \\
Gönlünden kopmak & Deyim & $63(2)$ & Yardımseverlik \\
\hline Toplam & & 3 adet & 2 değer \\
\hline
\end{tabular}

Türkçe ve Türk Kültürü 4-5. Sınıflar Dinleme Metinlerinde yer alan deyimler ve atasözleri değer kazandırma açısından incelendiğinde 2 adet deyimin 3 defa metinlerde kullanıldığ 1 görülmektedir. Deyimler; dayanışma (f:1) ve yardımseverlik (f:2) olmak üzere 2 farklı değerin kazandırılması açısından kullanılmıştır.

Türkçe ve Türk Kültürü 6-7. Sınıflar Ders Öğretim Materyalinde yer alan deyimler ve atasözlerinin değerler eğitimi açısından durumuna yönelik bulgular

Türkçe ve Türk Kültürü 6-7. Sınıflar Ders Öğretim Materyalinde hem deyim hem atasözlerinin değer kazandırmada rolü bulunmaktadır. Türkçe ve Türk Kültürü 6-7. Sınıflar Ders Öğretim Materyalinde yer alan deyim ve atasözlerinin değerler eğitimi açısından durumu aşağıdaki tabloda yer almaktadır.

Tablo 6: Türkçe ve Türk Kültürü 6-7. Sınıflar Ders Öğretim Materyalinde yer alan deyimler ve atasözlerinin değerler eğitimi açısından durumu

\begin{tabular}{llll}
\hline Atasözleri & Türü & $\begin{array}{l}\text { Sayfa Numarası/ } \\
\text { Kullanım Sıklı̆ı } 1\end{array}$ & Değerler \\
\hline Yolcu yolunda gerek & Atasözü & 61 & Sorumluluk \\
Afiyet (afiyet şeker) olsun & Deyim & 134 & Misafirperverlik \\
Hâl hatır (hâlini hatırını) sormak & Deyim & 169 & Dayanışma \\
Kafa kafaya vermek & Deyim & 24 & Dayanışma \\
Kusura bakmamak (kalmamak) & Deyim & 33 & Hoşgörü \\
Sadık kalmak & Deyim & 96 & Dürüstlük \\
(Birinin) Sırtını sıvazlamak & Deyim & 195 & Dayanışma \\
Ziyanı yok! & Deyim & 55 & Hoşgörü \\
Ziyaret etmek & Deyim & $24,118,129,154(2), 183(3)$ & Dayanışma \\
\hline Toplam & & 16 adet & 5 değer \\
\hline
\end{tabular}

Türkçe ve Türk Kültürü 6-7. Sinıflar Ders Öğretim Materyalinde yer alan deyimler ve atasözleri değer kazandırma açısından incelendiğinde 1 adet atasözü ve 8 adet deyimin 16 defa metinlerde kullanıldığı görülmektedir. Atasözü ve deyimler; sorumluluk (f:1), misafirperverlik (f:1), dayanışma (f:11), hoşgörü (f:2) ve dürüstlük (f:1) olmak üzere 5 farklı değerin kazandırılması açısından kullanılmıştır. 
Türkçe ve Türk Kültürü 6-7. Sınıflar Çalışma Kitabında yer alan deyimler ve atasözlerinin değerler eğitimi açısından durumuna yönelik bulgular

Türkçe ve Türk Kültürü 6-7. Sınıflar Çalışma Kitabında hem deyim hem atasözlerinin değer kazandırmada rolü bulunmaktadır. Türkçe ve Türk Kültürü 6-7. Sınıflar Çalışma Kitabında yer alan deyim ve atasözlerinin değerler eğitimi açısından durumu aşağıdaki tabloda yer almaktadır.

Tablo 7: Türkçe ve Türk Kültürü 6-7. Sınıflar Çalışma Kitabında yer alan deyimler ve atasözlerinin değerler eğitimi açısından durumu

\begin{tabular}{llll}
\hline Atasözleri & Türü & $\begin{array}{l}\text { Sayfa Numarası / } \\
\text { Kullanım Sıklığı }\end{array}$ & Değerler \\
\hline Ava giden avlanır & Atasözü & 39 & Dürüstlük \\
Ayağını yorganına göre uzat & Atasözü & 38 & Sorumluluk \\
Bakarsan bağ olur, bakmazsan dağ olur & Atasözü & 38 & Sorumluluk \\
Balık baştan kokar & Atasözü & 45 & Dürüstlük \\
Bir fincan kahvenin kırk yıl hatırı (hakkı) vardır & Atasözü & 39,123 & Yardımseverlik \\
Bugünün işini yarına bırakma & Atasözü & 40 & Sorumluluk \\
Misafir kımeti ile gelir & Atasözü & 68 & Misafirperverlik \\
Yalancının mumu yatsıya kadar yanar & Atasözü & $38,45,46$ & Dürüstlük \\
Kafa kafaya vermek & Deyim & $77(2)$ & Dayanışma \\
Kusura bakmamak (kalmamak) & Deyim & 65 & Hoşgörü \\
Sefa geldin (geldiniz) & Deyim & 55 & Misafirperverlik \\
Şehit düşmek (olmak) & Deyim & $59,167(2), 168$ & Vatanseverlik \\
Ziyaret etmek & Deyim & $79,93,219$ & Dayanışma \\
\hline Toplam & & 22 adet & 7 değer \\
\hline
\end{tabular}

Türkçe ve Türk Kültürü 6-7. Sınıflar Çalışma Kitabında yer alan deyimler ve atasözleri değer kazandırma açısından incelendiğinde 8 adet atasözü ve 5 adet deyimin 22 defa metinlerde kullanıldığı görülmektedir. Atasözü ve deyimler; dürüstlük (f:5), sorumluluk (f:3), yardımseverlik (f:2), misafirperverlik (f:2), dayanışma (f:5), hoşgörü (f:1) ve vatanseverlik (f:4) olmak üzere 7 farklı değerin kazandırılması açısından kullanılmıştır.

Türkçe ve Türk Kültürü Öğretmen Kılavuz Kitabı 6-7. Sınıflar Dinleme Metinlerinde yer alan deyimler ve atasözlerinin değerler eğitimi açısından durumuna yönelik bulgular

Türkçe ve Türk Kültürü Öğretmen Kılavuz Kitabı 6-7. Sınıflar Dinleme Metinlerinde Türk Çocukları İçin Türkçe Ve Türk Kültürü Dersi Öğretim Programı (1-10. Sınıflar)'nda yer alan temel değerlere (MEB, 2009) yönelik bulgular yer almamaktadır.

Türkçe ve Türk Kültürü 8-10. Sınıflar Ders Öğretim Materyalinde yer alan deyimler ve atasözlerinin değerler eğitimi açısından durumuna yönelik bulgular

Türkçe ve Türk Kültürü 8-10. Sınıflar Ders Öğretim Materyalinde hem deyim hem atasözlerinin değer kazandırmada rolü bulunmaktadır. Türkçe ve Türk Kültürü 8-10. Sınıflar Ders Öğretim Materyalinde yer alan deyim ve atasözlerinin değerler eğitimi açısından durumu aşağıdaki tabloda yer almaktadır. 
Tablo 8: Türkçe ve Türk Kültürü 8-10. Sinıflar Ders Öğretim Materyalinde yer alan deyimler ve atasözlerinin değerler eğitimi açısından durumu

\begin{tabular}{llll}
\hline Atasözleri & Türü & $\begin{array}{l}\text { Sayfa Numarası / } \\
\text { Kullanım Sılı̆̆ } 1\end{array}$ & Değerler \\
\hline Ayağını yorganına göre uzat & Atasözü & 40,41 & Sorumluluk \\
Gülü seven dikenine katlanır & Atasözü & $40(2)$ & Hoşgörü \\
Sürüden ayrılan kuzuyu kurt kapar & Atasözü & 40,41 & Dayanışma \\
El ele vermek & Deyim & 159 & Dayanışma \\
El uzatmak & Deyim & 237 & Yardımseverlik \\
Hâl hatır (hâlini hatırını) sormak & Deyim & 67 & Dayanışma \\
Ziyafet çekmek (vermek) & Deyim & $34,35(2)$ & Misafirperverlik \\
Ziyaret etmek & Deyim & $49,104,105,161,184$, & Dayanışma \\
& & 290,305 & \\
\hline Toplam & & 19 adet & 5 değer \\
\hline
\end{tabular}

Türkçe ve Türk Kültürü 8-10. Sinıflar Ders Öğretim Materyalinde yer alan deyimler ve atasözleri değer kazandırma açısından incelendiğinde 3 adet atasözü ve 5 adet deyimin 19 defa metinlerde kullanıldığ 1 görülmektedir. Atasözü ve deyimler; sorumluluk (f:2), hoşgörü (f:2), dayanışma (f:11), yardımseverlik (f:1) ve misafirperverlik (f:3) olmak üzere 5 farklı değerin kazandırılması açısından kullanılmıştır.

Türkçe ve Türk Kültürü 8-10. Sınıflar Çalıșma Kitabında yer alan deyimler ve atasözlerinin değerler eğitimi açısından durumuna yönelik bulgular

Türkçe ve Türk Kültürü 8-10. Sınıflar Çalışma Kitabında hem deyim hem atasözlerinin değer kazandırmada rolü bulunmaktadır. Türkçe ve Türk Kültürü 8-10. Sınıflar Çalışma Kitabında yer alan deyim ve atasözlerinin değerler eğitimi açısından durumu aşağıdaki tabloda yer almaktadır.

Tablo 9: Türkçe ve Türk Kültürü 8-10. Sınıflar Çalışma Kitabında yer alan deyimler ve atasözlerinin değerler eğitimi açısından durumu

\begin{tabular}{llll}
\hline Atasözleri & Türü & $\begin{array}{l}\text { Sayfa Numarası / } \\
\text { Kullanım Sıklı̆̆ }\end{array}$ & Değerler \\
\hline Ayağını yorganına göre uzat & Atasözü & 58,59 & Sorumluluk \\
$\begin{array}{l}\text { Bir elin nesi var, iki elin sesi var } \\
\text { Bugünün işini yarına bırakma }\end{array}$ & Atasözü & 57 & Dayanışma \\
$\begin{array}{l}\text { Danışan dağı aşmış, danışmayan düz } \\
\text { yolda şaşmış }\end{array}$ & Atasözü & 58 & Sorumluluk \\
Kusursuz dost arayan, dostsuz kalır & & 57 & Dayanışma \\
Yol göstermek & Atasözü & 58 & Hoşgörü \\
Ziyaret etmek & Deyim & 180 & Dayanışma \\
\hline Toplam & Deyim & $43,79,141,150,221$ & Dayanışma \\
\hline
\end{tabular}

Türkçe ve Türk Kültürü 8-10. Sınıflar Calıșma Kitabında yer alan deyimler ve atasözleri değer kazandırma açısından incelendiğinde 5 adet atasözü ve 2 adet deyimin 12 defa metinlerde kullanıldığı görülmektedir. Atasözü ve deyimler; sorumluluk (f:3), dayanışma (f:8), hoşgörü (f:1), olmak üzere 3 farklı değerin kazandırılması açısından kullanılmıştır.

Türkçe ve Türk Kültürü Öğretmen Kılavuz Kitabı 8-10. Sınıflar Dinleme Metinlerinde yer alan deyimler ve atasözlerinin değerler eğitimi açısından durumuna yönelik bulgular

Türkçe ve Türk Kültürü Öğretmen Kılavuz Kitabı 8-10. Sınıflar Dinleme Metinlerinde Türk Çocukları İçin Türkçe Ve Türk Kültürü Dersi Öğretim Programı (1-10. Sınıflar)'nda yer alan temel değerlere (MEB, 2009) yönelik bulgular yer almamaktadır.

Yurt Dışındaki Türk Çocukları İçin Türkçe Ve Türk Kültürü Dersi Öğretim Programı (1-10. Sinıflar)'nda (MEB, 2009) yer alan ve Türkçe ve Türk Kültürü Ders Öğretim Materyallerinde 
kazandırılmak istenen 12 temel değerden 8 tanesi atasözü ve deyimlerle kazandırılmaya çalışılmaktadır. Bu değerlerin sette yer alma durumu Tablo 10'da yer almaktadır:

Tablo 10: Temel değerlerin Türkçe ve Türk Kültürü Ders Öğretim Materyallerinde yer alma

\begin{tabular}{|c|c|c|c|c|c|c|c|c|c|}
\hline Değerler & $\begin{array}{l}\text { 1-3.S. } \\
\text { D.Ö.M. }\end{array}$ & $\begin{array}{l}1-3 . \\
\text { S. } \\
\text { Ç.K. }\end{array}$ & $\begin{array}{l}\text { 4-5.S. } \\
\text { D.Ö.M. }\end{array}$ & $\begin{array}{l}4-5 . \\
\text { S. } \\
\text { Ç.K. }\end{array}$ & $\begin{array}{l}\text { Ö.K.K. 4- } \\
\text { 5. S. } \\
\text { D.M. }\end{array}$ & $\begin{array}{l}\text { 6-7. S. } \\
\text { D.Ö.M } \\
\text {. }\end{array}$ & $\begin{array}{l}\text { 6-7. } \\
\text { S. Ç.K. }\end{array}$ & $\begin{array}{l}8-10 . \\
\text { S. } \\
\text { D.Ö.M }\end{array}$ & $\begin{array}{l}8-10 . \\
\text { S. Ç.K. }\end{array}$ \\
\hline Vatanseverlik & 1 & - & 2 & - & - & - & 4 & - & - \\
\hline Hoşgörü & - & - & 1 & - & - & 2 & 1 & 2 & 1 \\
\hline Misafirperverlik & 6 & - & 5 & 1 & - & 1 & 2 & 3 & - \\
\hline Dayanışma & 5 & 1 & 21 & 6 & 1 & 11 & 5 & 11 & 8 \\
\hline Sorumluluk & 2 & - & - & - & - & 1 & 3 & 2 & 3 \\
\hline Dürüstlük & - & - & - & - & - & 1 & 5 & - & - \\
\hline Yardımseverlik & 2 & - & - & - & 2 & - & 2 & 1 & - \\
\hline Estetik duyarlılık & - & - & - & 2 & - & - & - & - & - \\
\hline Toplam & 16 & 1 & 29 & 9 & 3 & 16 & 22 & 19 & 12 \\
\hline
\end{tabular}

Yurt dışında yaşayan iki dilli Türk çocukları için yazılan Türkçe ve Türk Kültürü Ders Öğretim Materyallerinde toplam 127 defa atasözü ve deyimlerin değer kazandırılma işlevinde kullanıldığı görülmektedir. Ders öğretim materyallerinde yer alan değerlerden vatanseverlik 7 defa, hoşgörü 7 defa, misafirperverlik 18 defa, dayanışma 69 defa, sorumluluk 11 defa, dürüstlük 6 defa, yardımseverlik 7 defa ve estetik duyarlılık 2 defa kullanılmıştır. $\mathrm{Bu}$ durum ders öğretim materyallerinde atasözü ve deyimler ile en fazla dayanışma değerinin kazandırılmaya çalışıldığını göstermektedir. Türkçe ve Türk Kültürü Ders Öğretim Materyallerinde dayanışma değerinin diğer değerlerden daha fazla kazandırılmaya çalışmasının nedeni olarak yurt dışında yaşayan Türklerin azınlık durumunda bulunması ve dayanışma içerisinde yaşamlarını daha rahat sürdürebilmeleri gösterilebilir.

Türkçe ve Türk Kültürü Ders Öğretim Materyallerinde en fazla kazandırılmaya çalışılan dayanışma değerinin 69 defa, en az kazandırılmaya çalışılan estetik duyarlılık değerinin 2 defa materyallerde yer alması değerlerin atasözü ve deyimlerle kazandırılmasında denge gözetilmediği sonucunu göstermektedir.

Türkçe ve Türk Kültürü 4-5. Sınıflar Çalışma Kitabında 29 atasözü ve deyimde değerler kazandırılmaya çalışılırken Türkçe ve Türk Kültürü 1-3. Sınıflar Çalışma Kitabında sadece 1 deyimde değer kazandırılmaya çalışılmıştır. Bu nedenle atasözü ve deyimlerle değer kazandırmada kitaplar arasında denge gözetilmediği sonucuna varılmıştır.

\section{Sonuç}

1-3. Sınıflar Ders Öğretim Materyali (1-3. S. D.Ö.M.), 1-3. Sınıflar Çalışma Kitabı (1-3. S. Ç.M.), Öğretmen Kılavuz Kitabı 1-3. Sınıflar Dinleme Metinleri, 4-5. Sınıflar Ders Öğretim Materyali (4-5. S. D.Ö.M.), 4-5. Sınıflar Çalışma Kitabı (4-5. S. Ç.K.), Öğretmen Kılavuz Kitabı 45. Sinıflar Dinleme Metinleri (Ö.K.K. 4-5. S. D.M.), 6-7. Sınıflar Ders Öğretim Materyali (6-7. S. D.Ö.M.), 6-7. Sınıflar Çalışma Kitabı (6-7. S. Ç.K.), Öğretmen Kılavuz Kitabı 6-7. Sınıflar Dinleme Metinleri, 8-10. Sınıflar Ders Öğretim Materyali (8-10. S. D.Ö.M.), 8-10. Sınıflar Çalışma Kitabı (810. S. Ç.K.) ve Öğretmen Kılavuz Kitabı 8-10. Sinıflar Dinleme Metinlerinden oluşan Türkçe ve Türk Kültürü Ders Öğretim Materyallerinde atasözü ve deyimlerin yeterli seviyede değer kazandırma işlevi olduğu görülmüştür.

Mete vd. (2018), makalelerinde Türkçe ve Türk Kültürü Dersi Öğretim Materyallerindeki atasözlerinin kitaplara dengeli dağılmadığ 1 sonucuna ulaşmışlardır. Bu çalışma atasözü ve 
deyimlerin değer kazandırma işlevi üzerinde durmaktadır. Bulgulara ulaşabilmek için atasözü ve deyimlerin hangi eserde ne kadar yer aldığı üzerinde de durulmalıdır. İnceleme sonucunda benzer bulgulara ulaşılmış, kitaplarda yer alan atasözlerinin ve deyimlerin dağılımındaki dengesizlik nedeniyle değerlerin kitaplara dengeli dağılmadığı görülmüştür.

Sapsağlam, Ö. (2016), Okul Öncesi Eğitim Programlarında Yer Alan Hedeflerin Değerler Açısından İncelenmesi adlı makalesinde incelenen son eğitim programı olan 2013 okul öncesi eğitim programının değerlere daha çok yer verdiği sonucuna ulaşmıştır. Bu çalışmanın veri toplama aracı olan materyallerin dayandığı programın alanı farklı olsa da ortaya konduğu yılların aynı döneme denk gelmesi açısından benzerlik göstermekte ve bu çalışmaya dayanak olan öğretim programı da değer kazanımına önem vermektedir.

Bulut M. (2013), makalesinde millî bir dil bilincinin ve millî şuurun gelişmesinde atasözleri ve deyimlerin etkin rol oynadığı sonucuna ulaşmıştır. Bu çalışmada incelenen atasözü ve deyimlerin en fazla dayanışma değerinin kazandırılmasında görev aldığı görülmektedir. Türkçe ve Türk kültürü ders öğretim materyalleri Türk dilinin öğretimi yanında Türk kültürünün öğretimine de önem vermektedir. Bu önem atasözü ve değerlerin değer kazandırmadaki rolünde de görülmektedir. $\mathrm{Bu}$ açıdan benzer sonuçlara ulaşılmıştır.

Deniz, K. ve Uysal B. (2010), makalelerinde ana dilini konuşmayan Türk asıllı çocukların ana dillerini tekrardan ancak yabancı dil öğretim yöntemleriyle edinebileceklerini, bu nedenle ana dili artık ortak kullanım dili değilse, ancak ikinci dil mantığıyla öğretilebileceğini belirtmişlerdir. Programda dil bilgisi kazanımları "Cümlelerde ad ve eylemin yanı sıra sıfat, zamir, zarf, edat, bağlaç ve ünlemlere de yer verilmelidir (MEB 2009: 4)" gibi genel ifadelerle tanımlanmak yerine aynı ders işleme sürecinde olduğu gibi bir başlık altında ele alınmalı ve kazanımlar net çizgileriyle belirlenmeli sonucuna ulaşmışlardır. Kazanımların net bir çizgiyle belirlenmemesi atasözü ve deyimlerin de dengesiz şekilde dağılmasına neden olmuş, bu durum atasözü ve deyimlerle değer kazandırılmasında da kitaplara dağılımda dengesizliğe neden olmuştur. Bu açıdan Deniz ve Uysal'ın elde ettiği sonuçlar bu çalışmanın sonuçlarının değerlendirilmesine 1şık tutmaktadır.

Araştırmanın sonuçlarından hareketle aşağıdaki önerilere yer verilmiştir:

1. İki dilli Türk çocuklarına Türkçe öğretmek için hazırlanacak yeni materyallerde kazandırılması gereken bütün değerlere yer verilmelidir.

2. İki dilli Türk çocuklarına Türkçe öğretmek için hazırlanacak yeni materyallerde kazandırılması gereken değerler materyallere dengeli dağıtılmalıdır.

3. Öğrencilere değer kazandırırken atasözü ve deyimlerden yararlanılmalıdır.

4. Değer kazandırmada atasözü ve değerler seviyelere göre hazırlanan materyallere yerleştirilmelidir.

5. İki dilli Türk çocuklarına değer kazandırmaya yönelik daha çok çalışma yapılmalıdır.

\section{Kaynakça}

Aksan, D. (1998). Her Yönüyle Dil Ana Çizgileriyle Dilbilim. TDK Yayınları.

Bulut, M. (2013). Türkçe Eğitimi Ve Öğretiminde Dil Ve Kültür Aktarımı Aracı Olarak Atasözleri Ve Deyimlerin Önemi. Turkish Studies, 8(13), 559-575. http://dx.doi.org/10.7827/TurkishStudies.5993

Bulut, S. (2011). Atasözlerinin Değerler Ĕ̆itimindeki Yeri. [Yayımlanmamış yüksek lisans tezi]. Karadeniz Teknik Üniversitesi Eğitim Bilimleri Enstitüsü. 
Deniz, K. \& Uysal, B. (2010). Avrupa Dilleri Öğretimi Ortak Çerçeve Metni Ve Yurt Dışındaki Türk Çocukları İçin Türkçe Ve Türk Kültürü Öğretim Programı. Türklük Bilimi Araştırmaları, 27(1), 239-261.

Ertuğrul, A. (2005). Yeni Müfredata Göre Edebî Kavramlar Sözlüğü. Zambak Yayınları.

Halstead, J. M., \& Taylor, M. J. (2000). Learning and Teaching about Values: A Review of Recent Research. Cambridge Journal of Education, 30(2), 169-203. https://doi.org/10.1080/713657146

Kaymakcan, R., \& Meydan, H. (2011). Din Kültürü ve Ahlâk Bilgisi Programları ve Öğretmenlerine Göre Değerler Eğitimi. Değerler Eğitimi Dergisi, 9(21), 29-55.

MEB. (2009). Yurt Dışındaki Türk Çocukları İçin Türkçe Ve Türk Kültürü Dersi Öğretim Programı (1-10. Siniflar). MEB Yayınlar1.

MEB, (2010). Türkçe ve Türk Kültürü Dersi Ders Öğretim Materyali (1-10. Sinıflar). MEB Yayınları.

MEB, (2010). Türkçe ve Türk Kültürü Dersi Çalışma Kitabı (1-10. Sinıflar). MEB Yayınları.

MEB, (2010). Türkçe ve Türk Kültürü Öğretmen Kılavuz Kitabı. MEB Yayınları.

Mete, F., Yeşilyurt, E. \& Keskin, H. (2018). İkidilli Türk Çocukları İçin Hazırlanan “Türkçe ve Türk Kültürü” Kitaplarında Atasözü Öğretimi. International Journal of Languages' Education and Teaching, 6(2), 174-183. http://dx.doi.org/10.18298/ijlet.2792

Sapsağlam, Ö. (2016). Okul Öncesi Eğitim Programlarında Yer Alan Hedeflerin Değerler Açısından $\begin{array}{llll}\text { İncelenmesi. } & \text { Turkish } & \text { Studies, } & \text { 683-700. }\end{array}$ http://dx.doi.org/10.7827/TurkishStudies.9571

Susar Kırmızı, F. (2014). 4. Sınıf Türkçe Ders Kitabı Metinlerinde Yer Alan Değerler. Değerler Ĕgitimi Dergisi, 12(27), 217-259.

TDK, “Güncel Türkçe Sözlük", [Online: http://tdk.gov.tr/ ] 20.03.2018 tarihinde erişildi.

Yıldırım, A., \& Şimşek, H. (2005). Sosyal Bilimlerde Nitel Araştırma Yöntemleri (5. Genişletilmiş Baskı). Seçkin Yayıncılık. 